\title{
AVALIAÇÃO DA QUALIDADE AMBIENTAL DO RIACHO LAMEGO PELA RAZÃO EPT/CHIRONOMIDAE E TESTE MICROBIOLÓGICO
}

\author{
Quality assessment of environmental of Riacho do Lamego by reason EPT/ chironomidae and microbiological test
}

\author{
KAIQUE KELVIN DE QUEIROZ DA SILVA ${ }^{1}$ \\ LAÍS CAROLLINE DO NASCIMENTO SIQUEIRA ${ }^{2}$ \\ DANIEL SILAS VERAS-DOS-SANTOS ${ }^{3}$ \\ CARLOS AUGUSTO SILVA DE AZÊEVDO ${ }^{4}$
}

RESUMO: A água é um recurso natural indispensável para a existência dos ecossistemas e das populações humanas. No entanto, ao longo do tempo, as ações antrópicas têm gerado a degradação quantitativa e qualitativa desse bem tão necessário à vida, em todas as suas tipologias, incluindo os mananciais, que são considerados fontes importantes para o abastecimento público. Dentro do perímetro do Campus do Instituto Federal do Maranhão no município de Caxias-MA, corre o Riacho Lamego que possui fitofisionomia de vereda, a qual representa importante papel como bacia coletora, por possibilitar a manutenção da perenidade de mananciais. Pelo exposto, considera-se necessária a realização de análise e monitoramento desse corpo hídrico, visando ao estabelecimento de seu diagnóstico qualitativo. Dessa forma, este trabalho avaliou a qualidade ambiental do Riacho Lâmego, por meio da medida bioindicadora Razão EPT (Ephemenoptera, Plecoptera e Tricoptera)/Chironomidae, que determina a relação entre organismos tolerantes e intolerantes à poluição ambiental, também foi feito uma avaliação da balneabilidade do riacho através de teste microbiológico de coliformes fecais.

Palavras-chave: Bioindicadores; qualidade da água; degradação.

\begin{abstract}
Water is a natural resource essential for the existence of ecosystems and human populations. However, over time, human actions have generated quantitative and qualitative degradation of this well so necessary to life, in all its types, including water sources, which are considered important sources for public supply. Within the perimeter of the campus of the Federal Institute of Maranhão of Caxias-MA, runs the Lamego stream, which has path of vereda physiognomy, which is important as collecting basin, by allowing the maintenance of perennial

\footnotetext{
${ }^{1}$ Acadêmico da Licenciatura em Ciências Biológicas do Instituto Federal do Maranhão Campus Caxias. email: kaique.queiroz01@hotmail.com.

${ }^{2}$ Acadêmica da Licenciatura em Ciências Biológicas do Instituto Federal do Maranhão Campus Caxias. email: laiscarolline21@yahoo.com.br

3 Professor do Instituto Federal do Maranhão Campus Caxias. email: daniel.veras@ifma.edu.br

${ }^{4}$ Professor da Universidade Estadual do Maranhão Campus Caxias. email: casazevedo@yahoo.com.br
} 
springs. For these reasons, it is considered necessary to perform analysis and monitoring of this water body, in order to establish its qualitative diagnosis. Thus, this study evaluated the envirometal quality of the Lâmego stream, by measuring bioindicator Reason EPT (Ephemenoptera, Plecoptera and Tricoptera) / Chironomids, which determines the relationship between tolerant and intolerant to environmental pollution organisms, it has also made an assessment of the stream bathing through microbiological testing of fecal coliforms. Keywords: Bioindicators; water quality; degradation.

\section{INTRODUÇÃO}

O crescimento das cidades ao longo dos últimos anos é o fator responsável pelo crescimento das atividades humanas sobre o meio ambiente e seus recursos. Em todo o planeta ecossistemas experimentam as consequências das atividades antrópicas de forma direta ou indireta, exemplos não faltam, desmatamento, contaminação de corpos hídricos e lençóis freáticos, introdução de espécies exóticas criando uma competição com espécies nativas e como consequência a diminuição da biodiversidade (GOULART; CALLISTO, 2003).

Os impactos ambientais, causados por ações antrópicas, têm levado a uma degradação da qualidade da água em diversos corpos hídricos, dificultando a utilização de tal recurso para a satisfação até mesmo das necessidades básicas humanas (CARDOSO; NOVAES, 2013).

Como o levantamento da características físico-químicas da água não se mostram eficientes para gerar um diagnóstico integral da qualidade da água, passou-se a utilizar a avaliação biológica dos corpos hídricos (BAPTISTA, 2008).

Para o desenvolvimento de ações de conservação é importante conhecer as condições em que se encontra o corpo hídrico, uma forma de se obter essa informação é utilizar bioindicadores, os quais podem ser considerados como: ferramentas que, se bem aplicadas, resumem informações de um determinado local e/ou atividade, facilitando a comunicação de informações técnicas e científicas tanto para os tomadores de decisão como para o público em geral (POLETO, 2010).

Existem diferentes métricas que se utilizam da comunidade de macroinvertebros bentônicos para avaliação da qualidade ambiental dos ambientes lóticos entre essas métricas podemos citar a razão EPT/Chironomidae, a qual leva em consideração a razão entre a abundância entre os táxons Ephemenoptera, Plecoptera e Tricoptera, cuja maior parte dos táxons são sensíveis a poluição (POLETO, 2010; SILVEIRA 2004) e Chironomidae que geralmente são 
tolerantes a condições extremas de baixa oxigenação, já que são comuns em ambientes com forte impacto químico e efluentes domésticos (CETESB, 2004).

O corpo de água que recebe matéria fecal passa a ser potencialmente perigoso à saúde humana, nesse sentido a avaliação dos Coliformes fecais (Termotolerantes) é considerada importante decorrente de os mesmos estarem relacionados a microrganismos causadores de gastroenterites (BARBOSA et al, 2012; WORLD HEALTH ORGANIZATION, 2011).

Apesar da crescente utilização das águas para fins recreacionais, nota-se uma carência de estudos e programas de monitoramento que avaliem as condições de balneabilidade, especialmente em balneários de águas doces, o que proporciona o contato de banhistas com águas contaminadas por efluentes domésticos e industriais (LOPES; MAGALHÃES Jr, 2010).

O presente trabalho teve por objetivo avaliar a qualidade da água do riacho Lamego através da medida bioindicadora EPT/Chironomidae e coliformes fecais.

\section{MATERIAIS E MÉTODOS}

\section{Área de estudo}

O estudo foi realizado no riacho Lamego no município de Caxias, Maranhão, nos seguintes pontos de coleta: próximo as nascentes do riacho Lamego localizado nas proximidades do residencial Eugenio Coutinho, na área do IFMA-Campus Caxias.

O clima da região segundo Koopen é do tipo sub-úmido seco, com temperatura média anual de $27^{\circ} \mathrm{C}$, precipitação pluviométrica entre $1600 \mathrm{~mm}$ a $2000 \mathrm{~mm}$. A vegetação predominante é o cerrado, exibindo variações que vão desde o cerrado ralo até o cerradão, com alguns trechos entremeados por babaçuais e buritizais (CONCEIÇÃO; RUGGIERI, 2010).

Os pontos de coleta de água para análises, microbiológica e de macroinvertebrados foram referenciados através do uso de GPS GARMIN Etrex 30, em coordenadas UTM, a cartografia foi realizada com os softwares ArcGIS 9.3 (Figura 1). 

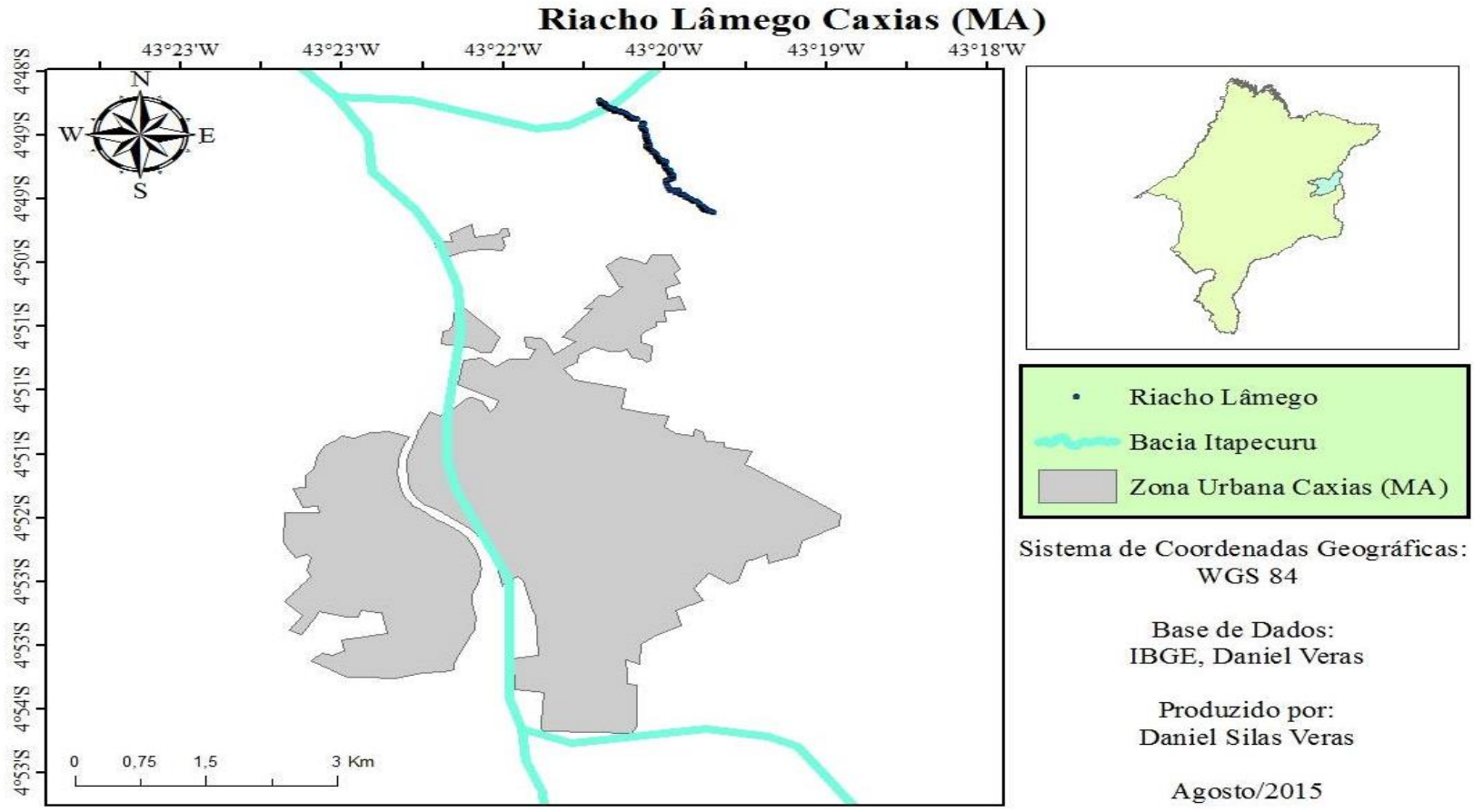

Sistema de Coordenadas Geográficas: WGS 84

Base de Dados: IBGE, Danie1 Veras

Produzido por: Daniel Silas Veras

Agosto/2015

\section{Coletas e análises de bioindicadores}

Figura 1: Riacho Lâmego, Bacia do Itapecuru, Caxias (MA).

A coleta da comunidade bentônica de imaturos de insetos foi realizada com amostrador tipo súber de malha $0,25 \mathrm{~mm}$ ou puçá com tela de nylon de malha de $0,5 \mathrm{~mm}$, material coletado foi transferido para sacos plásticos e fixado em álcool 70\% e etiquetados com os dados de local e data de coleta.

No laboratório, as amostras foram lavadas em água corrente em um sistema com duas peneiras, a primeira de malha com $2 \mathrm{~mm}$ de abertura e a segunda com 0,5 mm, após a lavagem foi realizada a triagem onde os organismos foram retirados com pinça de relojoeiro $\mathrm{n}^{\mathrm{o}} 5$ de aço.

Os espécimes encontrados foram conservados em álcool $70 \%$ e etiquetados. A classificação ao nível de família foi realizada com o auxílio de microscópios estereoscópio, e chave de identificação de Mugnai, Nessimian \& Baptista (2010), Costa, Ide \& Simonka (2006) e Hamada et al. (2014).

A razão EPT/Chironomidae é calculada somando-se os indivíduos de ordem Ephemeroptera, Plecoptera, Trichoptera (EPT), e esse número é dividido pelo somatório de EPT mais o total de larvas da família Chironomidae coletados no mesmo local (GONÇALVES, 2007; SILVEIRA, 2004).

Por essa medida, a água apresenta melhor qualidade, quanto mais próxima de (1) for o valor calculado, conforme as classes de qualidade da agua definidas na Figura 2 (GONÇALVES, 2007). 


\begin{tabular}{c|c}
\hline $\begin{array}{c}\text { Porcentagem de } \\
\text { EPT }\end{array}$ & $\begin{array}{c}\text { Qualidade da } \\
\text { água }\end{array}$ \\
\hline $75 \%-100 \%$ & Muito Boa \\
\hline $50 \%-74 \%$ & Boa \\
\hline $25 \%-49 \%$ & Regular \\
\hline $0 \%-24 \%$ & Ruim \\
\hline
\end{tabular}

Fonte-Gonçalves, 2007.

Figura 2: Classe de qualidade e significado dos valores do índice EPT/Chironomidae.

As coletas para análises bacteriológicas foram realizadas por cinco semanas consecutivas, como o recomendado pela resolução CONAMA 274/2000. Para obtenção dos coliformes fecais existentes na água foi utilizado o método dos tubos múltiplos. A quantificação da quantidade de coliformes para essa técnica foi realizada através do método de simplificação, denominado "Número Mais Provável” (NMP).

Os resultados obtidos nos testes microbiológicos foram comparados com os parâmetros constantes na Resolução CONAMA no 274/2000 (Figura 3) que dispõe sobre a balneabilidade das águas brasileira.

\begin{tabular}{|c|c|c|}
\hline \multirow[t]{2}{*}{ Categoria } & & Caracterização \\
\hline & Excelente & $\begin{array}{l}\text { Quando } 80 \% \text { do número de amostras coletadas nas cinco } \\
\text { semanas anteriores, em um mesmo local, apresentarem um } \\
\text { limite de: } 250 \text { Coliformes Fecais, } 200 \text { Escherichia coli por } 100 \\
\text { mililitros. }\end{array}$ \\
\hline \multicolumn{3}{|l|}{ Própria } \\
\hline & Muito boa & $\begin{array}{l}\text { Quando } 80 \% \text { do número de amostras coletadas nas cinco } \\
\text { semanas anteriores, em um mesmo local, apresentarem um } \\
\text { limite de: } 500 \text { Coliformes Fecais, } 400 \text { Escherichia coli por } 100 \\
\text { mililitros. }\end{array}$ \\
\hline & Satisfatória & $\begin{array}{l}\text { Quando } 80 \% \text { do número de amostras coletadas nas cinco } \\
\text { semanas anteriores, em um mesmo local, apresentarem um } \\
\text { limite de: } 1000 \text { Coliformes Fecais, } 800 \text { Escherichia coli por } 100 \\
\text { mililitros. }\end{array}$ \\
\hline
\end{tabular}




$\begin{array}{ll}\text { Imprópria } & \text { Imprópria } \\ & \text { coliformes fecais (termotolerantes) ou } 2000 \text { Escherichia coli por } \\ & 100 \text { mililitros; }\end{array}$

Figura 3: Categoria das águas doces destinadas a balneabilidade adaptado da Resolução CONAMA 274/2000.

\section{RESULTADOS E DISCUSSÃO}

$\mathrm{Na}$ triagem de macroinvertebrados foram coletadas outras ordens, como: Odonata, hemíptera e Coleóptera, também coletou-se representantes do Filo Mollusca e do Filo Annelida pertencentes classe oligoqueta e hirudínea sendo esses resistentes a poluição. Os grupos taxonômicos que compõe a macrofauna bentônica podem ser formados por uma comunidade complexa e de elevada diversidade, sendo as oligoquetas e os hirudíneos bastante comuns nos ambientes aquáticos continentais (ESTEVES, 2011).

Os resultados para razão EPT/Chironomidae podem ser observados na tabela 1, referente a cada ponto de coletado.

\begin{tabular}{cccc}
\hline PONTOS & EPT & CHIRONOMIDAE & EPT/CHIRONOMIDAE \\
\hline P1 & 4 & 468 & 0,008 \\
P2 & 12 & 251 & 0,045 \\
P3 & 397 & 616 & 0,391 \\
P4 & 283 & 832 & 0,253 \\
\hline
\end{tabular}

Fonte: Laboratório de Biiologia - IFMA Campus Caxias

Tabela 1: Abundancia de EPT, Chironomidae e Razão EPT/Chironomidae.

Pelos valores do índice EPT/Chironomidae é possível perceber que os pontos P1, P2, possuem a qualidade da água muito ruim, e um grau de severa poluição orgânica, já no ponto P3 e P4 percebe-se o aumento de organismos sensíveis, mas em contrapartida há o aumento juntamente de organismos resistente, dessa forma apresentando a qualidade da água apenas como ruim.

Estudos realizados na região central do estado de São Paulo em riachos de paisagem agrícola na qual foi utilizado a mesma métrica obtiveram uma qualidade ruim para 10 de 12 riachos amostrados (TANAKA et al, 2015).

Nota-se ainda que os pontos P1 e P2 possuem a pontuação mais baixa, isso pode ser explicado devido aos pontos estarem próximos as nascentes do riacho Lamego, onde o mesmo sofre um forte impacto, em decorrência da urbanização próximo ao local e consequente perca de mata ciliar, fato que tende a reduzir a heterogeneidade dos habitats e propiciar a presença de organismos resistentes como os da família Chironomidae (SAULINO; CORBI; CARACCIOLI, 2011). 
Nos pontos P3 e P4 os quais passam na área do IFMA é observado uma pequena melhora na qualidade, essa diferença pode ser caracterizada pelo fato de que esses pontos apresentam sua vegetação ripária mais conservada, dispondo de maior quantidade de microhábitats, e não sofrerem despejo direto de efluentes domésticos. A qualidade do hábitat é um dos fatores mais importantes no sucesso de colonização e estabelecimento das comunidades biológicas em ambientes lênticos ou lóticos (AMORIN; CASTILLO, 2009).

Os Resultados obtidos na análise microbiológica das cinco coletas consecutivas realizadas no riacho Lamêgo, podem ser observados na tabela 2.

\begin{tabular}{cccccc}
\hline $\begin{array}{c}\text { PONTOS } \\
\text { DE COLETA }\end{array}$ & $\begin{array}{c}\text { COLETA 1 } \\
\text { NMP/100ml }\end{array}$ & $\begin{array}{c}\text { COLETA 2 } \\
\text { NMP/100ml }\end{array}$ & $\begin{array}{c}\text { COLETA 3 } \\
\text { NMP/100ml }\end{array}$ & $\begin{array}{c}\text { COLETA 4 } \\
\text { NMP/100ml }\end{array}$ & $\begin{array}{c}\text { COLETA 5 } \\
\text { NMP/100ml }\end{array}$ \\
\hline P1 & $>1100$ & 460 & $>1100$ & $>1100$ & 210 \\
P2 & $>1100$ & 460 & $>1100$ & $>1100$ & $>1100$ \\
P3 & 290 & 1100 & $>1100$ & 290 & 1100 \\
P4 & $>1100$ & 460 & 290 & 1100 & 1100 \\
\hline
\end{tabular}

Fonte: Laboratório de Microbiologia - IFMA Campus Caxias

Tabela 2: Parâmetros microbiológicos das amostras coletadas no riacho Lamêgo.

De acordo com a RESOLUÇÃO CONAMA n 274/2000, os níveis de contaminação observados no riacho Lamego, revelam que as águas do riacho estão impróprias para balneabilidade, altos índices de material fecal podem decorrer do lançamento de efluentes domésticos, devido a presença de núcleos habitacionais (LOPES; MAGALHÃES Jr, 2010; FONTANELLA et al., 2009).

\section{CONCLUSÃO}

A avaliação da qualidade da água do riacho Lamego através da medida bioindicadora EPT/Chironomidae indica que a qualidade do habitat está ruim, principalmente em decorrência da perca da mata ciliar e do despejo de efluentes domésticos.

Com base nos parâmetros da Resolução CONAMA n 274/2000 com o qual os dados obtidos nos testes microbiológicos foram comparados, foi diagnosticado que todos os quatro pontos estudados encontram-se impróprios para balneabilidade.

Isso indica a necessidade da aplicação de projetos que visam à revitalização desse corpo hídrico como também a sensibilização e conscientização da população quanto aos impactos causados pela ação do homem no meio ambiente, desenvolvendo assim um pensamento de conservação do ecossistema local. 


\section{AGRADECIMENTOS}

Ao IFMA pela concessão da bolsa de PIBIC.

\section{REFÊRENCIAS}

AMORIN, A.C. F. CASTILLO, A. R. Macroinvertebrados bentônicos como bioindicadores da qualidade da água do baixo rio Perequê, Cubatão, São Paulo, Brasil. BIODIVERS.

PAMPEANA, v. 7, n.12, 2009.

BAPTISTA, D. F. Uso de macroinvertebrados em procedimentos de biomonitoramento em ecossistemas aquáticos. Oecol. Bras., 12 (3): 425-441, 2008.

BARBOSA, C. C. et al. Qualidade microbiológica da água consumida em bebedouros de uma unidade hospitalar no Sul de Minas. REAS, Revista Eletrônica Acervo Saúde, 2012. Vol. 4 (1), 200-211.

CARDOSO, R. S.; NOVAES, C. P. Variáveis Limnológicas e Macroinvertebrados Bentônicos como Bioindicadores de Qualidade da Água. Revista Nacional de Gerenciamento de Cidades, v. 01, n. 05, 2013, pp. 16-35

CESTEB. Protocolo para o biomonitoramento com as comunidades bentônicas de rios e reservatórios do estado de são Paulo. São Paulo: CESTEB, 2012. Disponível em:

$<$ http://www.cetesb.sp.gov.br/agua/aguas-superficiais/129-manuais-e-protocolos > Acesso em: 23 de agosto. 2015.

CONAMA, 2000. Resolução CONAMA no 274, de 29 de novembro de 2000. Brasília-DF (Brasil), Conselho Nacional de Meio Ambiente, Ministério do Meio Ambiente.

CONCEIÇÃO.; G. M. RUGGIERI, A. C. Ocorrência e importância de Hidrolea spinosa L. (Hidrolaphyllaceae), Caxias, Maranhão-Brasil. Rev. Acta Tecnológica, v. 5, n.1, 2010.

ESTEVES, F. A. Fundamentos de limnologia. 3 ed. Rio de Janeiro. Interciência, 2011.

FONTENELLA, A. et al. Diagnóstico ambiental da bacia hidrográfica doRio da Ilha, Taquara, Rio Grande do Sul, Brasil. R. bras. Bioci., Porto Alegre, v. 7, n. 1, p. 23-41, jan./mar. 2009.

GONÇALVES, Análise comparativa de índices bióticos de avaliação de qualidade da água, utilizando macroinvertebrados, em um rio litorâneo do estado do Paraná. Curitiba, 2007. Dissertação-Universidade Federal do Paraná.

GOULART, M. D. C.; CALLISTO, M. Bioindicadores de Qualidade de Água como Ferramenta em Estudos de Impacto Ambiental. Revista da FAPAM, ano 2, n. 1, 2003.

LOPES, F. W. A.; MAGALHÃES Jr., A. P. Avaliação da Qualidade das Águas para Recreação de Contato Primário na Bacia Do Alto Rio das Velhas -MG. Hygeia 6(11): 133-149, Dez/2010. 
MUGNAI, R.; NESSIMIAN, J. L.; BAPTISTA, D. F. Manual de identificação de macroinvertebrados aquáticos do estado do Rio de Janeiro. 1 ed. Rio de Janeiro: Techinical Books, 2010.

POLETO, C. Introdução ao gerenciamento ambiental. Rio de Janeiro: Interciência, 2010.

SAULINO, H. H. L.; CORBI, J. J.; CARACCIOLI, L. C. Avaliação da qualidade da água da nascente do Ribeirão das Anhumas (Araraquara-SP) através do estudo dos macroinvertebrados aquáticos. REVISTA UNIARA, v.14, n.1, julho 2011.

SILVEIRA, M. P.; QUEIROZ, J. F.; BOEIRA, R. C. Protocolo de coleta e preparação de amostras de macroinvertebrados bentônicos em riachos. Jaguariuna: Embrapa Meio Ambiente, 2004.

TANAKA, M. O. et al. Redundância entre métricas da qualidade ambiental de riachos em paisagem agrícola. Rev. Ambient. Água, vol.10 no.4 Taubaté Oct./Dec. 2015.

WORLD HEALTH ORGANIZATION, 2011. Guidelines for drinking-water quality . 4 th ed. Disponível em:

http://www.who.int/water_sanitation_health/publications/2011/dwq_guidelines/en/. Acesso em: 23 agost. 2015. 